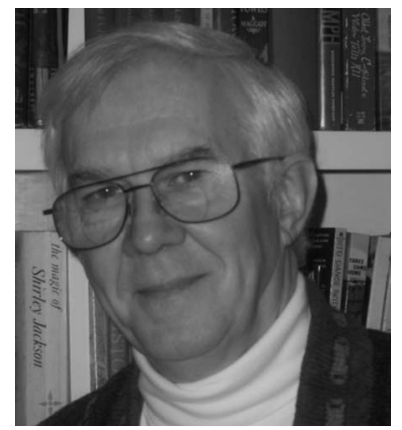

\section{A New Editor}

In January 2008, SPIE's Board of Directors passed a resolution establishing a 10-year term limit for journal editors to take effect in 2010. Because I began my editorship in 1998, at the end of this year I will have served for 11 years. Although this is a 12-year span, I did not serve as Editor while I was SPIE President in 2000. The late Roger Lessard served as Editor that year.

So, I will be stepping down at the end of this year. To choose my successor, a subcommittee of the SPIE Publications Committee was formed. It consisted of Harry Levinson, the chair of the Publications Committee, who served as chair; a member of the SPIE Executive Committee, Brian Culshaw; myself; Robert Magnusson, an Optical Engineering Editorial Board member; and two members of the Publications Committee, Scott Teare and Philip Stahl. The subcommittee solicited nominations from the leadership, staff, and optical engineering community. After much deliberation, we submitted a recommendation to the SPIE Board of Directors. Upon approval by the Board, an invitation was extended to our top selection to serve as Editor of Optical Engineering. The person selected, Dr. Ronald Driggers, accepted the post.

Ron is currently the superintendent of the Optical Sciences Division at the Naval Research Laboratory (NRL) and researcher in the field of innovative optical detection systems. He brings more than 20 years of experience in the field of electro-optics to the position. His breadth in the field is demonstrated by the three books on infrared and electro-optics systems that he has written, the 100plus papers he has published, and the Encyclopedia of Optical Engineering (Marcel Dekker) that he edited. In addition to his current work at NRL, he was the director of the Modeling and Simulation Division at the U.S. Army's Night Vision Laboratory.

Prior to this appointment as Editor, Ron has had a considerable involvement with SPIE. He was co-chair on a series of three conferences titled "Electro-Optical and Infrared Systems: Technology and Applications" in 2004, 2005, and 2006 and author of an SPIE Tutorial Text,
Analysis of Sampled Imaging Systems, with Rich Vollmerhausen. He also served as my Associate Editor in the fields of infrared systems and radiometry from 1998 until 2005 and followed that with a stint at Applied Optics.

I am pleased that Ron will be succeeding me. He is a working researcher aware of the important advances in optical engineering and has a broad knowledge of the field. To my mind, the biggest initial challenge of any editor is to assemble a Board of Editors that can handle papers in their field in a deliberate manner and who have the depth of knowledge to be able to render decisions fairly and with a perception of technical journalism that can sort the important from the unimportant for the readers and the field they know. I think Ron will do a fine job picking members for the Board of Editors. In June, after Ron had accepted the position, he came down to Atlanta and we went over the various tasks that the Editor has to perform. We talked about choosing Board members and about establishing and maintaining standards. We discussed topics for editorials and how I went about writing them. On that aspect of editorship, I was not very helpful. I have no set procedure for writing an editorial and the motivation for writing about some topic depends on what concerns me or arouses my curiosity.

Over the years, working with Ron as an Associate Editor for Optical Engineering, as a colleague on the Publications Committee, and as the new Editor of Optical Engineering, I can say that over the next years this journal is in good hands. I wish him well, particularly on those days when some odd-ball problem that no one could have ever anticipated lands on his desktop, ready for his analysis and disposition.

Donald C. O'Shea

Editor 